\title{
İKTİSAT LİTERATÜRÜNDE DÖRDÜZ AÇIKLAR HİPOTEZİ VE TÜRKIYYE EKONOMİSİ ÜZERİNE BİR ARAŞTIRMA
}

Hüseyin TEZER 1

$\ddot{O Z Z}$

Anahtar Kelimeler:
Makroekonomi
İktisat Politikası
İkiz Açıklar Hipotezi
Üçüz Açıklar Hipotezi
Dördüz Açıklar Hipotezi

JEL Kodlar:

A10, B40, B41

C01, C02

\author{
Received Date (Başvuru Tarihi): 26/03/2020 \\ Accepted Date (Kabul Tarihi): 28/04/2020 \\ Published Date (Yayın Tarihi): 25/06/2020
}

\section{QUADRUPLE DEFICITS HYPOTHESIS IN ECONOMICS LITERATURE AND A STUDY ON ECONOMICS OF TURKEY}

\section{ABSTRACT}

Keywords:

Macroeconomy

Twin Deficit Hypothesis

Triple Deficit Hypothesis

Quadruple Deficit Hypothesis

JEL Codes:

A10, B40, B41

C01, C02
The "quadruple deficit hypothesis", which is one of the recent discussion topics, is a new theory developed on the effects of the relations between output (balance) deficit, investment-savings, public budget and current account deficit (balance) on the economy. Although there is extensive literature on "twin deficits" and "triple deficits" in the literature of literature, there has not been enough study in the context of quadruple deficits and their effects on the economy. This is the reason that this works in terms of quadruplets hypothesis to explain Turkey's economy in recent years through the selected data will be made an empirical examination. The econometric methodology applied in the study consists of three parts. In the first part; Stability levels of the series are carried out using Lee-Strazicich unit root test with structural break. Secondly; The existence of a cointegration relationship between variables is determined within the framework of the ARDL boundary test. Finally, the existence and direction of causality between variables is investigated by Toda-Yamamoto causality analysis. In the conclusion part, the empirical findings are interpreted in the light of the macroeconomic data obtained.

${ }^{1}$ Dr. Öğr. Üyesi, Bilecik Şeyh Edebali Üniversitesi. İ.İ.B.F. İktisat Bölümü. huseyin.tezer@bilecik.edu.tr 


\section{GİRIŞ}

Bu çalışmada yatırım- tasarruf açığı, kamu bütçe dengesi açığı, cari açık ve çıktı açığının eşanlı olarak görülmesi olarak ifade edilen "dördüz açıklar hipotezi" nin Türkiye ekonomisinde, 2001-2019 arasındaki etkisinin ampirik bir incelemesi yapılmaktadır. İktisat literatüründe "ikiz açıklar" ve "üçüz açıklar" üzerinde çok geniş bir literatür bulunmasına rağmen, dördüz açıklar ve ekonomi üzerindeki etkileri hakkında henüz çok geniş bir literatür oluşmamıştır. Özellikle 2008 dünya ekonomik krizinden sonra yaşanan ekonomik gelişmeler bu yeni yaklaşım üzerinde ilgiyi artırmıştır. Son yıllarda hem gelişmiş hem de gelişmekte olan ekonomilerde sıklıkla karşılaşılan ve ekonomilerde kırılganlıklar yaratan yatırım-tasarruf açığı, kamu bütçe dengesi açığı, cari işlemler dengesindeki açık ve çıktı açığının aynı anda görülmesine ekonomide "dördüz açıklar2" denmektedir. Bu çalışmada; dördüz açıklar hipotezinin iktisat görüşleri açısından değerlendirilmesiyle beraber Türkiye ekonomisinde özellikle ekonomideki yansımaları incelenerek neden sonuç ilişkileri bağlamında değerlendirilmesine çalışılmıştır. İktisadi görüşe göre "İkiz $A c ̧ \imath k$ " bir ekonomide bütçe açığı ve cari işlemler açığının aynı anda görülmesidir. Diğer bir ifadeyle bütçe açıkları, cari açığa neden olurken, cari açık da bütçe açı̆̆ını etkileyen bir olgu olarak görülmektedir. Üçüz açık hipotezine ise ikiz açıklara yatırım- tasarruf açı̆̆ının da eklenmesi sonucu ulaşılmaktadır. Ekonominin iç dengesini oluşturan yatırım-tasarruf dengesi ve bütçe dengesi ile birlikte ekonominin dış dengesini oluşturan cari işlemler dengesi aynı anda açık veriyorsa buna "üçüz açıklar" sorunu denmektedir. Bir başka ifadeyle ikiz açık hipotezinin genişletilerek bütçe ve cari açığına, tasarruf açığının da eklenmesiyle oluşan bir durumdur. Dördüz açıklar hipotezi ise; son yıllarda yapılan akademik çalışmalarda yer bulmaktadır ve henüz yeni bir ifade olarak değerlendirilmektedir. İktisat literatüründe henüz geniş bir yer bulmamasına rağmen ekonomilerde kırılganlık yaratan etkin bir hipotez olarak görülmektedir. Bundan dolayıdır ki çalışmada dördüz açıklar hipotezi bağlamında Türkiye ekonomisinin son yıllardaki verileri üzerinden bir değerlendirilmesi yapılmaktadır. Dördüz açıklar

2 Ünsal, (2009). İkiz ve üçüz açıklardan ayrı olarak, söz konusu bu açıkların kaynağını oluşturduğu şeklinde ifade edilebilen bir diğer unsur ise çıktı açığı boşluğudur. Bir ekonomideki veri teknoloji ve bütün üretim faktörlerinin tam olarak kullanılması durumunda üretilebilecek maksimum mal ve hizmet miktarının parasal ifadesi olan potansiyel ya da tam istihdam gayri safi yurtiçi hasıla (Baumol ve Blinder 1985) düzeyi dikkate alınarak hesaplanmaktadır. 
probleminin anılan yıllar içinde ekonomi üzerindeki etkileri incelenerek yorumlanacaktır. Çalışmanın giriş bölümünden sonra ikinci bölümünde iktisat literatüründe dördüz açıklar hipotezi ile ilgili iktisadi görüşlere yer verilecek ve iktisat literatüründe dördüz açıklar üzerine yapılan çalışmalar ve fikirlere yer verilecektir. Üçüncü bölümde ise Türkiye ekonomisinin incelenen yıllar arasındaki bir dönemde makroekonomik verilerden yararlanılarak ekonomik sonuçların dördüz açıklar hipotezi bağlamında ampirik bir çalışması yapılacaktır. Çalışmada uygulanan ekonometrik metodoloji üç bölümden oluşmaktadır. Birinci bölümde; serilerin durağanlık seviyeleri yapısal kırılmalı Lee-Strazicich (2004) birim kök testi kullanılarak gerçekleştirilmektedir. İkinci bölümde; belirlenen değişkenler arasındaki eş bütünleşme ilişkisinin varlığı Pesaran vd. (2001) tarafından geliştirilen ARDL sınır testi çerçevesinde belirlenmektedir. Nihai olarak değerlendirilen değişkenler arasındaki nedensellik ilişkisinin varlığı ve yönü Toda -Yamamoto (1995) nedensellik analizi ile araştırılmaktadır. Son bölümde ise Türkiye ekonomisinin 2001-2019 arası bir dönem aralığındaki makroekonomik verilerden oluşturulan ekonometrik analizler çerçevesindeki neden-sonuç ilişkilerinin değerlendirilmesi ve makroekonomik önerilerin sunulmasıyla sonuçlanmaktadır.

\section{DÖRDÜZ AÇIKLAR HİPOTEZİ BAĞLAMINDA İKTİSADİ TEORİK ANALIZİ VE AMPİIIK LITTERATÜR TARAMASI}

Dördüz açıklar hipotezi bağlamında yapılan bu çalışmada ilk önce kavramsal olarak tanımlanan cari açık ve bütçe açığı arasındaki pozitif yönlü ilişki; literatürde "ikiz açık”" olarak adlandırılmakta ve bütçe açığının artırıcı etkisine yönelik aktarım mekanizması iki farklı hipotez ile incelenmektedir. Bu hipotezlerden ilki Keynes'in Gelir- Harcama modeli üzerinden değerlendirilmekte ve bütçe açıklarının tüketim harcamaları kanalıyla artırdığı milli gelirin, ithalatı, dolayısıyla da dış ticaret açığının yükselmesiyle sonuçlandığını gösterilmektedir. Mundell-Fleming yöntemine dayanan diğer hipotez ise "Feldstein Zinciri" olarak ifade edilmektedir. Bu varsayıma göre bütçe açıklarında görülen herhangi bir artış, faiz oranlarının da neden olduğu yabancı

\footnotetext{
${ }^{3}$ Yıldırım, (2009). Devletin topladığı vergiden fazla harcama yapması ve bu farkı dış ülkelerden karşılaması durumunda ortaya çıkmaktadır.
} 
sermaye girişlerine, sermaye girişlerine bağlı ulusal para değerlenmesine ve diş ticaret açıklarının da yükselmesine neden olmaktadır (İpek \& Kızılgöl, 2016, s. 425).

Keynesyen görüşe göre, bir ülke ekonomisindeki vergi oranlarının azalması ya da kamu harcamalarının artması ulusal tasarruflarını da azaltmakta ve bütçe açıklarının yükselmesine neden olmaktadır. Bütçe açıklarının büyümesine bağlı olarak artan faiz oranları ve yükselen faiz seviyesi ülkeye yabancı sermaye girişlerini tetikleyerek döviz artışlarına neden olarak döviz kuru değerlerini düşürür ve yerli paranın değerlenmesine neden olur (Akıncı vd. 2016, s. 26). Keynesyen ekonomi yaklaşımında bütçe büyüklügünü ve dengesini toplam talebi etkileyen temel değişkenler arasında görmekte ve gerektiğinde ekonominin genel dengesi uğruna bütçe dengesinden fedakârlık edebileceğini öngörmektedir. İkinci dünya savaşı sonrası yıllardan itibaren uygulama alanı bulan bu politika anlayışı, zaman içinde bütçe açıklarına dayalı ortaya çıkan kamu borç yükünün büyük boyutlara ulaşması nedeniyle, iktisat yazınında ciddi eleştirilere neden olmuştur. Ancak diğer taraftan 1970'lerden itibaren bir başka görüşe göre ise kamu borçlarının hiç de öne sürüldüğü gibi sorunlara yol açmadığı savunulmuştur. "Ricardocu Denklik Yaklaşımı" olarak bilinen bu görüş kamu borçlarının tasarrufları ve sermaye birikimini etkilemediği savunulmaktadır (Y1ldırım vd. 2009, s. 449). "Ricardo'cu Denklik Teorisi”, vergi indirimi ile finanse edilen borcun tüketim üzerinde etkisinin olmayacağı üzerinedir. Ricardo'cu görüşe göre; tüketiciler gelecek üzerinde tahminler yapar ve bu yüzden harcama kararları yalnızca mevcut gelire göre değil aynı zamanda gelecekteki gelir beklentilerine göre oluşmaktadır. İleri görüşlü tüketici bugünkü kamu borçlanmasını gelecekte daha yüksek vergi anlamına geleceği görüşünden hareket etmektedir. Kamu borçlanmasıyla finanse edilen bir vergi indirimi vergi yükünü azaltmamakta, sadece kısıtlı bir şekilde ödemeyi geciktirmektedir. İşte bu yüzden tüketicinin daha fazla harcamasını teşvik etmeyecektir (Mankiw, 2009, s. 492-493).

Bütçe açı̆̆ı ve cari işlemler açığının, yani diğer bir ifadeyle ikiz açıklarının, tasarruf-yatırım dengesinin katılmasıyla meydana gelen üçüz açıklar son yıllarda

\footnotetext{
${ }^{4}$ Ricardo'cu Denklik Hipotezi; Hükümetin vergi indirimini ya da kamu harcamasını artırarak ekonomiye müdahale etmesi karşısında kişiler harcamalarını artırmak yerine tasarruflarını artırırlar. Bunun nedeni ise bireylerin, hükümetin oluşan bütçe açıklarını kapatmak için tekrar vergileri artıracaklarını öngörmeleridir.
} 
ekonomi literatüründe çok araştırılan konular arasında yer almaktadır. İkiz açıklarda görülen bütçe açıkları, cari işlemler dengesinde oluşan açıkları pozitif yönde etkilediği düşünülmektedir. Daha açık bir ifadeyle belirtmek gerekirse; bütçe açıkları, cari işlemler dengesinde de açığa neden olmakta ve cari açık da bütçe açıklarını etkilemektedir. Kısaca iki taraflı bir etkileşim söz konusudur.

Buradan hareketle; 1 nolu denklemde $(S$ - T) özel kesim yatırım - tasarruf dengesini, $\quad(T-G)$ kamu bütçe dengesini, ya da diğer bir ifadeyle kamu kesimi geliriyle, harcamaları arasındaki farkı, $(X-M)$ ise dış ticaret dengesini, ya da diğer bir ifadeyle ithalat- ihracat arasındaki farkı göstermektedir ${ }^{5}$.

$$
(S-I)+(T+G)=(X-M)
$$

Bu denklemde görülen semboller açısından tasarruflar ve yatırımlar (S - I) değerlendirilmesi üç şekilde incelenmelidir.

$(S<I)=>\quad B u$ durumda özel kesimin tasarrufları, yatırımlarını karşılayamamaktadır ve tasarruf açı̆̆ı söz konusudur. Tasarruf açığım olan ülkenin yatırımlarını sürdürebilmek için dış tasarrufa (ülke dışı sermayeye) ihtiyaç duyması demektir. Bu da ülkenin dış borcunun artmasına neden olmaktadır.

$(S=I)=>$ Bu durumda özel kesim tasarrufları yatırımlara denktir ve tasarruf yatırım dengesi söz konusudur. Böyle bir denklikte ülke tasarruflarıyla yatırımlarını karşılayabildiğinden dış borçlanma gereği yoktur.

$(S>I)=>$ Bu durumda özel kesimin tasarrufları yatırımlardan çoktur ve tasarruf fazlası söz konusudur. Tasarruf fazlası veren ülkeler, ellerindeki tasarruf fazlası olan kaynakları tasarruf açı̆̆ı olan ülkelere yönlendirerek gelir elde edebilmekte ve tasarruf açı̆̆ı olan ülkelerdeki yatırım ve tüketim imkanlarını etkilemektedirler.

Kamu gelirleri (vergiler ve diğer gelirler) ve kamu harcamaları ( $T$ - G) arasındaki ilişkininde de aynı yolla ifade edilmesi sonucu şu şekilde gösterilebilir.

${ }^{5}$ Yıldırım vd. (2009). Makro Ekonomi. 
$(T<G)=>$ Bu durumda kamu gelirleri, kamu harcamalarından azdır ve bu da kamu bütçe açı̆̆ı'nı göstermektedir.

Kamu kesimi borçlanma gereğinin yükselmesi sonucunda kamusal borçlanmaya gidilmesi özel kesim üzerinde gelecekte bir servet artışına neden olmaktadır. Bu görüşe göre, kamu bütçe dengesindeki açı̆̆ın borçlanmayla finanse edilmesinin neden olduğu özel kesim gelirlerindeki artış, özel kesimin harcamaları üzerinde de önemli bir artışa ve dolayısıyla fiyatlar genel seviyesinde ve faiz haddinde muhtemel bir artışa neden olmaktadır.

Ricardocu Denklik Hipotezi'ne (Ricardian Equivalence Hypothesis) göre, bütçe açı̆̆ının finanse edilebilmesi için yapılan borçlanmanın, sonraki dönemde faiziyle birlikte ödenebilmesi için bir sonraki dönem vergilerinin de artırılmasına neden olacaktır. İşte bu nedenledir ki bugün yapılan borçlanma yükü (vergi indirimi) sonraki dönmeler için yeniden vergi artışları anlamına gelmektedir (Çetin, 2014, s. 68).

Kamu bütçe dengesinde karşılaşılan açıklar üç şekilde finanse edilebilmektedir. İlk olarak kamu gelirlerini artıracak maliye politikaları devreye girmektedir. Bunlar ilk olarak vergilerdeki artışlar olarak öne çıkmaktadır. Vergilerde görülen artışlar tüketici gelirlerindeki harcama paylarını azalttı̆̆ı için tüketim harcamalarının da azalmasına neden olmaktadır. Bir iktisat politikası olarak bu yöntemin seçilmesi, enflasyonist bir baskının olduğu durumlarda uzun vadede enflasyonu da baskılayan bir unsur olarak ortaya çıkmaktadır. Diğer yandan bütçe açıklarının kapatılması açısından vergilerin ve diğer gelirlerin artırılması kamu açıklarının kapatılmasında etkin bir yöntem olarak görülmektedir. İkinci finansman yolu ise doğrudan kamu borçlanması seçeneğinin tercih edilmesidir. Bu şekilde borçlanma tercihi iki şekilde ortaya çıkmaktadır. Bunlar ise iç ve dış borçlanma şekilleri olarak öne çıkmaktadır. Borçlanma vadeleri konu dışında tutulduğunda iç borçlanma yolu tercih edildiğinde ülke içi tasarruflarının yatırım ve tüketime ayrılan kısmının kamu kesimini finanse etmek amaciyla kullanılması iktisatta "Crowding-Out6" denen dişlama etkisine neden

${ }^{6}$ Crowding-Out; Ekonomilerde kamu bütçe açıklarını finanse edebilmek için cari piyasadan borçlanma gereği duymaktadır. Kamunun borç seviyesinin yükselmesi ve iç piyasadan borçlanması piyasa faiz oranlarının artmasıyla sonuçlanmaktadır. Yükselen faiz oranları yatırımların da maliyetini artırmaktadır. Sonuç olarak ekonomideki yatırımların azalışıyla sonuçlanan bu sürece Crowding-Out - Dişlama Etkisi denmektedir. 
olabilir ve bu durum hem yatırımların hem de tüketim harcama seviyelerin azalmasına neden olarak ekonomide bir sonraki dönemde büyüme oranlarının düşmesine neden olabilmektedir. Ekonomik büyüme (GSYH) oranı üzerindeki azalış eğilimi işsizliğin artışına neden olabilir. Aynı zamanda ekonomik büyümedeki gerileme bir sonraki dönemde kamu gelirlerinin azalmasına neden olarak kamu kesimi borçlanma gereğinin (KKBG) daha fazla yükselmene de neden olabilir. Ve bu sarmal kamu borç oranlarının hızla yükselmesiyle sonuçlanabilir. Kamu bütçe dengesindeki açıklar için üçüncü borçlanma tercihi ise dış borç yolunun tercih edilmesidir. Bu tür borçlanma kısa ve uzun vadeli hazine bonolarıyla yapılmaktadır. $\mathrm{Bu}$ tür borçlanmalarının olumsuz yanı ise kamu açıklarının, kamu zararlarının kapatılması için veya gelir getirmeyen alt yapıların finansmanı için yapılır ise gelecek dönemde kamu bütçe dengesi üzerinde olumsuz baskılara, faiz artışlarına ve ekonomik daralmalara neden olabilmektedirler (Karanfil \& Kılıç. 2015. S. 3).

Genel açıklamaların yapılmasını müteakip makroekonomik dengeler tek tek formüller yoluyla aşağıda açıklanmaktadır.

$(T=G)=>B u$ durumda kamu gelirleri ile kamu harcamaları eşittir ve (denk bütçe) kamu bütçesi denktir. Kamu bütçesinde denk olması gelirler ve giderlerin eşit olması anlamına gelmekte ve denk bütçe anlayışı olması demektir. Kamuda bütçe dengesi olduğunda kamu kesimi borçlanma gereği yoktur fakat ekonomiler merkez bankası ve para politikalarına yön vermek için politik olarak kamu borçlanması yapabilirler. Bu tür borçlanmalar daha çok uzun vadeli borçlanmalar olarak görülmektedir.

$(T>G)=>$ Bu durumda ise kamu gelirleri, kamu harcamalarından fazladır ve kamu bütçesi fazla veriyor demektir. Bu durumda ekonomide borçlanma gereği yoktur fakat hükümetler ikinci denklikteki gibi politik borçlanma yoluna gidebilmektedir. Ekonominin gelişimine göre transferleri, sübvansiyonları veya özel kesim yatırımlarını destekleyen harcama artırıcı tedbirler alabilirler. Bu tür uygulamalar ekonomik büyümeyi de hızlandırmaktadır. 
Denklemin son eşitliği ise ihracat ve ithalat arasındaki denkliği $(X-M)$ meydana getiren dış ticaret denkliğidir.

$(X<M)=>$ Bu durum ihracatın ithalattan az olduğu anlamına gelmekte ve diş ticarette açık verildiğini (dış ticaret açı̆̆ı)göstermektedir. İhracatın ithalattan az olduğu durumlarda, açığın boyutuna göre diğer gelirler sabit olduğu varsayımında cari işlemler dengesi açık verecektir. Cari işlemler dengesi; bir ülkenin dış dünyayla yaptığ1 alış-veriş, sermaye giriş-çıkışlarının negatif yönlü olması demektir. Cari işlemler dengesi dış ticarete bağımlı bir seyir izlemektedir ve cari işlemler dengesinin açık veya fazla vermesini belirleyen asıl unsur dış ticaret dengesindeki açıktır. Cari işlemler dengesindeki açık ancak dövizle karşılanabilir olduğundan bu açıklar ya ülkenin daha önceden biriktirmiş olduğu döviz rezervlerinden (altın ya da yabancı konvertible paralar) karşılanacak, ya da diş borçlanma yoluyla karşılanacaktır. Sürdürülebilir dış borç yapısı olduğu sürece bu açıklar ülkenin risk faktörünün belirlediği faiz oranlarında borçlanma sürdürülecektir. Sürdürülebilir diş borç ilişkisi Cari Açık / GSYH oranıyla değerlendirilmektedir. Cari işlemler açığı gayri safi yurt içi hasıla arasındaki oran eşik değerleri geçtiğinde ülke ekonomisi açısından bir ekonomik kırılganlık belirtisi olarak algılanmakta ve krizlerin zeminini hazırlamaktadir.

$(X=M)=>$ Bu durum ise ithalat ile ihracat eşit olduğunu ve diş ticarette bir denge olduğunu göstermektedir. Diş ticaret dengesi olan ülkelerde diğer diş gelirler sabit varsayımı altında dış borçlanma gereği yaratmamaktadır.

$(X>M)=>$ Bu durum ise ihracatın ithalattan fazla olmasını göstermekte ve ülke ekonomisi ihracat fazlası (dış ticaret fazlası) verdiği anlamına gelmektedir. Ülke ekonomisinin dış ticaret fazlası veren ülkeler aynı zamanda tasarruf fazlası da vermektedirler. Dış ticaret fazlasının oluşturduğ tasarruf fazlaları dış ticarete dayalı cari işlemler dengesi açı̆̆ı veren ülkelere akarak tasarruf gelirlerine neden olmaktadır.

Yukarıda verilen 1-no'lu denklemdeki üç kesiminde aynı anda açık pozisyonunda olması durumu üçüz açıklar probleminin doğmasına neden olmaktadır. Yani yazı ile ifade edildiğinde; (Tasarruf Açı̆̆ı $)+($ Bütçe Açı̆̆ı $)=($ Cari 
Açık) olarak ifade edilen denklemin sonucunda üçüz açıklar oluşmaktadır. Üçüz açıkların sürdürülebilirliği ekonomideki gelişmelere doğrudan etki eden unsurdur. Son yıllarda birçok gelişmiş ekonomide görülen bütçe açıkları azalışlarına rağmen cari işlemler dengesindeki açıkların artması dikkat çekici bir konu haline gelmiştir. Diğer yandan gelişmekte olan ülkeler için kalkınmanın en önemli unsuru milli gelirin önemli bir kısmının yatırımlara ayrılmasıdır. Ekonomik büyüme sürecinde yatırımların finansörü olan tasarruflar, bu ülkeler için bir darboğaz haline dönüşebilmektedir. Milli gelirin yetersizliğinden kaynaklanan düşük seviyeli tasarruflar yatırımlar için yetersiz kalmakta ve verimliliğin yükselmesini de olumsuz etkilemektedir. Sonuçta yetersiz tasarrufların yatırımları tam olarak finanse edememe durumu, ülke ekonomilerinin GSYH büyüme seviyesini de olumsuz etkilemektedir (Akıncı vd. 2016, s. 27). Ya da diğer bir ifadeyle ikiz ve üçüz açıklar çıktı açığının da temel sebepleri arasında yer aldığı anlamına gelmektedir.

Araştırmanın temel konusu olan "iktisatta dördüz açiklar" problemi üçüz açıklara "çıktı açı̆̆ı"nın ilave edilmesiyle ulaşılan ekonomik durum olarak ifade edilmektedir. Ya da bir başka ifadeyle, çıktı açı̆̆ı, en basit şekliyle bir ekonomideki mevcut üretim ya da reel üretim düzeyinin potansiyel üretim seviyesinden farkına denmektedir. Ekonominin gerçekleşen fiili çıktısı ile potansiyel çıktı düzeyi arasındaki farkın ekonomik ölçüsü olarak da görülebilir. Potansiyel çıktı miktarı, ekonominin tam istihdam durumunda olduğu zaman üretebildiği maksimum mal ve hizmet miktarı olarak tanımlanmaktadır. Tam istihdam durumu, ekonominin tam kapasitede çalıştığ 1 anlamına gelmektedir. Çıktı açı̆̆ı durumu ise, ekonomideki kaynakların hem aşırı hem de eksik çalıştırılması sonucunda ekonomide görülen verimsizlik miktarı olarak ifade edilebilir.

2 ve 3' nolu eşitlikte görülen potansiyel GSYİH seviyesi, işsizlik haddinin doğal işsizlik düzeyine eşit olduğu durumdaki reel GSYİH seviyesini göstermektedir. Eşitlikten de görüldüğü gibi belirli bir dönemde reel GSYİH, potansiyel GSYİH'dan daha yüksek veya daha düşük olabileceği gibi, her iki sonuç değeri de birbirine eşit olabilir. İşte bu yüzden çıktı açı̆̆ı, reel GSYİH seviyesinin, potansiyel GSYİH seviyesinden daha küçük olduğu durumlarda meydana gelmektedir (Akınc1, 2016, s. 
28). GSYİH'nın yükselip- düşerken, çıktı açığı da pozitif veya negatif olmak üzere iki şekilde de görülebilir. Ancak her iki durum da istenen bir süreç değildir. İktisat literatüründe pozitif çıktı açı̆̆ı, fiili çıktının tam-kapasite çıktısından fazla olması durumunda ortaya çıkar. Böyle bir ekonomik sonuç, talebin çok yüksek olması durumunda gerçekleşmekte ve firmalar bu talebi karşılamak için olması gereken etkin kapasitelerinin çok üzerinde bir üretim için çalışmaktadırlar. Negatif çıktı açığında ise, fiili çıktı miktarının ekonomi tam kapasitedeyken üretebileceğinden daha az üretmesi durumunda ortaya çıkmaktadır.

Çıktı Açı̆̆ı = Reel GSYH - Potansiyel GSYH

$$
\text { Çılktı Açı̆̆ } \iota=\frac{\text { Reel GSYH-Potansiyel GSYH }}{\text { Potansiyel GSYH }}
$$

Aşağıda verilen 4, 5, ve $6^{\prime}$ numaralı formüllerde belirtilen eşitliklerde; $Y_{R}$, Reel GSYİH ve Yp ise, Potansiyel GSYİH düzeyini yansıtmaktadır. Eşitliklerde özel kesim tasarruf ve yatırım dengesi $(I-S)$ ile kamu kesimi gelir ve gider dengesi $(G-T)$ toplamının cari dengeye $(M-X)$ eşit olduğunu ve söz konusu bu üç dengenin GSYİH dengesi $\left(Y_{R}-Y_{p}\right)$ belirlendiği görülmektedir. Bu doğrultuda potansiyel GSYH'ya kıyasla reel GSYH'nin yetersiz kalmasına bağlı olarak kendini gösteren tasarruf açı̆̆ı, üçüz açık problemine eşlik ederek "iktisatta dördüz açıklar" sorununa dönüşmektedir (Akinc1, 2016, s. 28).

$$
\begin{gathered}
\left(Y_{R}-Y p\right)=C+I+G+(X-M)+C+S+T \\
\left(Y_{R}-Y p\right)=I+G+X=S+T+M \\
\left(Y_{R}-Y p\right)=(I-S)+(G-T)=(M-X)
\end{gathered}
$$

İktisat literatüründe dördüz açıklar hipotezi ile ilgili çok geniş bir yazın havuzu henüz oluşmamıştır. Bu konulardaki çalışmalar genelde daha çok ikiz ve üçüz açıklar üzerine yoğunlaşmaktadır. Bu konuda yerli literatürde Akıncı vd'nin (2016) birlikte oluşturduğu ve 1980 ile 3013 yılları arasındaki bir dönem aralığında ele aldıkları çalışmada; Türkiye ekonomisinde cari işlemler dengesindeki açıkları etkileyen temel faktörler, tasarruf- yatırım ve bütçe açılarının, üçüz açıklarının temel unsuru ise 
kaynakların etkin kullanılamaması sonucu ortaya çıkan çıktı açığı yüzünden olduğu fikrine varmışlardır. Anılan yıllar açısından Türkiye için dördüz açıkların geçerli olduğunu ileri sürmüşlerdir.

Tülümce'nin (2013), 1984-2010 arası bir dönem için yaptığı ampirik çalışmada uygulanan "VAR" modeli sonucu birim kök testleri, belirlenen değişkenlerin birinci farklılık düzeylerinde durağan olduğu sonucuna varmıştır. Ancak değişkenlerde uzun dönemli ortak bir hareketin (eş-bütünleşme) olmadığını ileri sürmüştür. Yapılan VAR analizleri sonucunda elde edilen bulgular, cari açıkların nedeninin yatırımtasarruf açıkları olduğunu ortaya koyarken bütçe açığı ile cari açık arasında karşılıklı bir etkileşimin de var olduğunu ileri sürmüştür. Türkiye' de ülke içi yatırım- tasarruf dengesinin bozulması (özel kesimin yatırım- tasarruf açığının artmasıyla) cari açı̆̆a neden olmaktadır. Bütçe açıkları ve yatırım- tasarruf açıkları arasındaki etkileşim cari açık üzerinde pozitif bir etki yaratmaktadır. Ülke ekonomisinde bir kesimin yaşadığ1 tasarruf açı̆̆ının diğer kesimin sahip olduğu tasarruf fazlası ile giderilmeye çalışılmasına rağmen giderilemediği durumunda ise dış kaynak yoluyla finansman ile gerçekleştirilmeye çalışılmaktadır. Bu durum ülke ekonomisinde yatırım- tasarruf açı̆̆ından cari açı̆̆a doğru bir etkileşim meydana getirmektedir.

Karanfil \& Kılıç'ın (2015), 1980-2013 dönemi aralığında üçüz açıklar hipotezi açısından yaptıkları bir ampirik çalışmada ise; aynı anda görülen üçüz açığın, birbirleri arasındaki ilişkiler incelenmiş ve elde edilen ekonometrik verilere göre, eş bütünleşme analizi sonucunda üçüz açıklar değişkenleri arasında uzun dönemli karşılıklı bir ilişkinin var olduğu kanısına varmışlardır. Yapılan çalışmada değerlendirilen nedensellik analizi sonucunda da değişkenler arasında çift yönlü bir ilişkinin bulunmasıyla beraber üçüz açı hipotezinin söz konusu dönem için Türkiye ekonomisinde geçerli olduğu görüşü ortaya çıkmıştır.

Kaygısız ve arkadaşlarının (2016) yaptığı bir çalışmada ise ilk olarak yatırımtasarruf, büyüme ve cari denge değişkenlerinin gelişim eğilimleri incelenerek, TodaYamamoto ve Granger testleri aracılığıyla belirlenen dört değişken arasındaki nedensellik ilişkisi 1980-2014 aralığındaki bir dönem için test edilmiştir. Yapılan çalışma sonucunda ulaşılan nedensellik testi verileri, büyüme, tasarruf ve yatırım 
değişkenleri arasında anlamlı bir nedensellik ilişkisinin bulunmadığı sonucuna varılmıştır. Aslında teorik beklentiler tasarruflardan yatırımlara ve aynı zamanda yatırımlardan büyümeye doğru bir ilişkinin varlığını gerektirse de çalışmadaki nedensellik analizi sonuçları bu çerçevedeki bir sonuca götürmemiştir. Ancak, büyüme, tasarruf ve yatırım değişkenlerinden cari dengeye doğru tek yönlü bir nedensellik ilişkisi olduğu tespit edilmiştir. GSYH ekonomik büyümeden cari açığa doğru tek yönlü bir nedensellik ilişkisinin varlığı, Türkiye'de yaşanılan cari açık sorununun yüksek büyüme dönemlerinde daha hızlı arttığı tezini destekler görülmektedir.

Göçer ve Akın'ın (2016) yaptığı bir başka çalışmada ise; Türkiye ekonomisinin benzer ülkelerin (Brezilya, Endonezya, Hindistan, Güney Afrika) ekonomileri ile karşılaştırılması sonucunda istikrarlı ve etkin bir iktisadi büyüme, bu ekonomilerin tamamının başlıca hedeflerinden biri olduğu üzerinedir. Bu nedenle bu ülkelerin GSYH ekonomik büyümeleri, finansal yapıları, küresel dünya ekonomileriyle entegrasyonu, iç ve dış talep yapıları, yurt içi tasarruf ve yatırımları, iktisat literatüründe sıklıkla tartışılan konular arasında yer almaktadır. İncelenen bu çalışmada; kırılgan beşli olarak adlandırılan "Brezilya, Endonezya, Hindistan, Güney Afrika ve Türkiye" gibi ülkelerde yatırım- tasarruf açığ1 ile ekonomik büyüme arasındaki ilişkiler ekonometrik olarak analiz edilmiş ve bu ülkelerin en temel özellikleri; tasarruf açıkları vermeleri ve ekonomik büyüme için dışa bağımlı olmalarıdır. Yapılan ampirik analizler sonucunda; ülkelerin tasarruf açıkları ile büyümeleri arasında negatif yönlü bir ilişki olduğu görülmektedir. Yani bu ülkelerin tasarruf açı̆̆ının artması, büyüme oranlarının azalmasına neden olmaktadır.

\section{3. İKTISATTA DÖRDÜZ AÇIKLAR HIPOTEZİ, METEDOLOJİ VE TÜRKIYYE EKONOMISII ÜZERINE AMPIRİK BULGULAR}

Bu çalışmada ilk olarak dördüz açık teorisini test edebilmek amacıyla oluşturulan regresyon modeli (7)’ nolu denklemde gösterilmektedir.

$$
G S Y H D_{t}=\alpha_{0}+\alpha_{1} Y T D_{t}+\alpha_{2} C D_{t}+\alpha_{3} B D_{t}+u_{1 t}
$$


Yukarıda verilen denklemde GSYHD; çıktı dengesini, YTD; yatırım ve tasarruf dengesini, CD; cari dengeyi ve BD; bütçe dengesini temsil etmektedir. Modelde a0 sabit terimi, ut ise hata terimlerini göstermektedir. Çalışma için oluşturulan regresyon modelinde yer alan a1, a2 ve a3 katsayıları sırasıyla yatırım ve tasarruf dengesinin, cari dengenin ve bütçe dengesinin, çıtı dengesi üzerindeki uzun dönemli etkisini göstermektedir. Çalışmada kullanılan GSYHD, YTD, CD ve BD serileri Strateji ve Bütçe Başkanlığı (2020) ile Dünya Bankası (2020) veri sitesinden elde edilen veriler derlenerek oluşturulmuştur. Tablo 1'deki çalışmada kullanılan değişkenlere bağlı mod, medyan, minimum, maksimum, çarpıklık, basıklık değerleri gibi niteleyen istatistiklere yer verilmekte ve Grafik 1'de ise serilerin 1983-2019 döneminde izlediği eğilimi görülmektedir.

Tablo 1. Niteleyici İstatistikler (Zaman Serisi: 1983-2019)

\begin{tabular}{ccccc}
\hline İstatistikler & GSYHD $^{*}$ & YTD $^{* *}$ & CD $^{* * *}$ & BD $^{* * * *}$ \\
Ortalama & 4.560 & -1.798 & -2.413 & -3.644 \\
Medyan & 0.944 & -2.521 & -1.825 & -2.534 \\
Maximum & 6.449 & 4.920 & 1.911 & -0.588 \\
Minimum & -10.626 & -9.402 & -8.945 & -12.158 \\
Standart Sapma & 4.295 & 3.805 & 2.586 & 2.934 \\
Çarpıklık & -0.955 & 0.076 & -0.384 & -1.451 \\
Basıklık & 3.190 & 1.773 & 2.485 & 4.391 \\
Gözlem & 37 & 37 & 37 & 37 \\
\hline
\end{tabular}



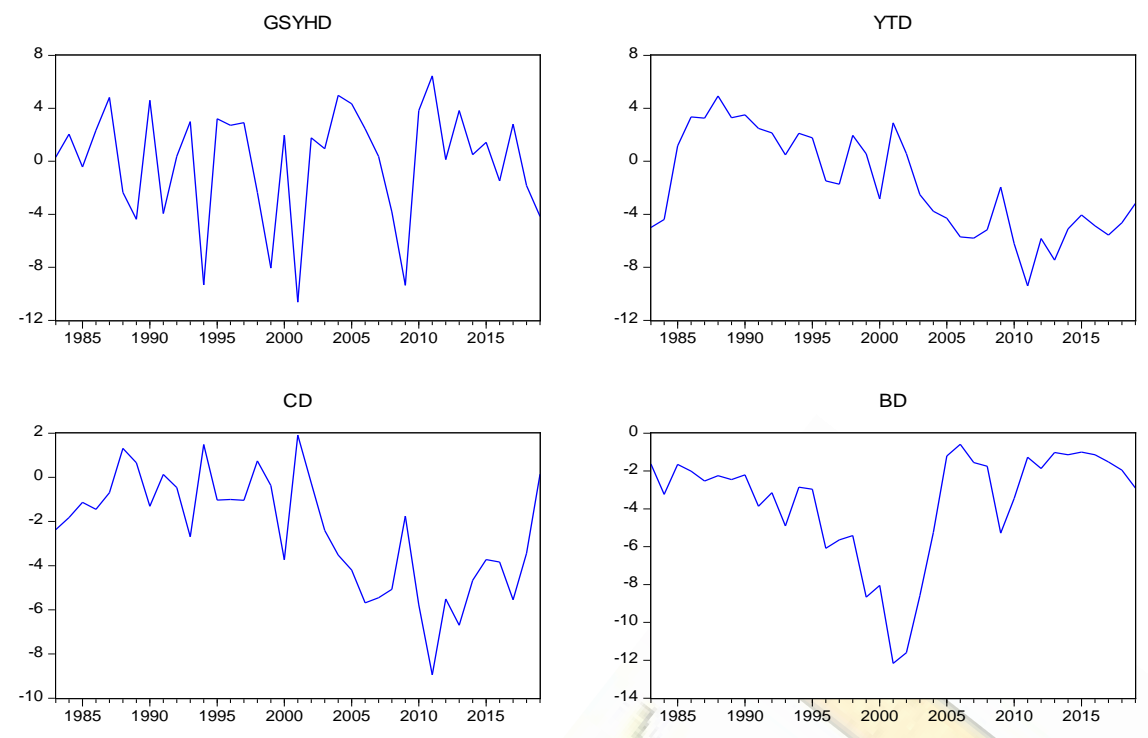

Grafik 1. Serilerin Zaman İçerisindeki Seyri (1983-2019)

\subsection{Ekonometrik Metodoloji}

$\mathrm{Bu}$ projeksiyonda uygulanan ekonometrik metodoloji üç bölüm itibariyle oluşmaktadır. Birinci bölümde oluşturulan serilerin durağanlık seviyeleri, yapısal kırılmalı Lee-Strazicich (2004) birim kök testi kullanılarak gerçekleştirilmektedir. İkinci bölümde ise; belirlenen değişkenler arasındaki eş bütünleşme ilişkisinin etkisi, Pesaran vd.'nin (2001) geliştirdiği bu olgu ARDL sınır testi çerçevesinde belirlenmektedir. Nihai olarak değişkenler arasındaki nedenselliğin varlığı ve yönü Toda -Yamamoto (1995) nedensellik analizi ile araştırılmaktadır.

\subsection{Lee-Strazicich Birim Kök Testi}

Geleneksel birim kök testlerinde kırılmaların yok sayılması, uygulanan testin yanıltıcı sonuçlar vereceği düşüncesinden hareketle çeşitli yapısal kırılmalı birim kök testleri öne çıkmaktadır. Lee-Strazicich (2004) geliştirdiği tek yapısal kırılmalı birim kök testi ile sabit terimli ve trendsiz ile sabit terimli ve trendli modeller olan "crash" ve "break" modelleri vasıtasıyla serilerin durağanlık mertebeleri belirlenmektedir (Tabar ve Çetin, 2016, s. 86). Çalışmada kullanılan sabitli terimli ve trendsiz model olan "crash" modeli için veri üretim süreci (8) numaralı denklemde gösterilmektedir:

$$
\mathrm{Y}_{\mathrm{t}}=\Delta \mathrm{z}_{\mathrm{t}}+\mathrm{e}_{\mathrm{t}} \quad \mathrm{e}_{\mathrm{t}}=\beta \mathrm{e}_{\mathrm{t}-1}+\varepsilon_{\mathrm{t}} \quad \varepsilon_{\mathrm{t}} \sim \text { iid }\left(0, \mathrm{\sigma}^{2}\right)
$$


Denklemde yer alan ' $Z_{t}^{\prime}$ içsel değişkenleri içeren vektörü belirtmektedir. Sabit terimli ve Trendsiz olarak kabul edilen "Crash" modelinde $D_{t}, t \geq T B+1$ iken diğer durumlarda 0 değerini alan kukla değişkeni, " $M Z_{t}=M S B$ * $M Z a^{\prime \prime}$ denkleminde $Z_{t}$ yerine $\left[1, t, D_{t}\right]$ konularak elde edilmektedir. TB ise kırılma tarihini göstermektedir (Altınöz, 2017, s. 70).

LM prosedürüne göre belirlenen test istatistiği (9) numaralı denklemden elde edilmektedir:

$$
\Delta Y_{t}=\delta \Delta Z_{t}+\emptyset S_{t-1}+\varepsilon_{t}
$$

Denklemde yer alan $S t=Y t-\psi x-Z t \delta, t=2, \ldots, T$ ve $\psi x$ ise $Y t-Z t \delta$ ile belirlenmektedir. Ayrıca $\delta ; \Delta \mathrm{Yt}^{\prime}$ nin $\Delta \mathrm{Zt}^{\prime}$ ye regresyonundan elde edilen katsayıları göstermektedir. $\Delta \mathrm{Zt}$; 'Crash' modeli için $[1, \beta \mathrm{t}]$ ile tanımlanmaktadır.

\subsection{ARDL Sinır Testi}

Seriler arasındaki eş bütünleşme ilişkisinin varlığı yani, değişkenler arasında uzun dönemli ilişkinin var olup olmaması Pesaran vd. (2001) tarafından geliştirilen ARDL sınır testi prosedürü yardımıyla belirlenebilmektedir. Serilerin $\mathrm{I}(0)$ ve I(1) olması durumunda uygulanabilirliği ve yapısal kırılmalı birim kök testlerinden elde edilen kırılmanın bu prosedüre eklenebilmesi testin en önemli özelliklerinden biridir (Şahin ve Gökdemir, 2016, s. 14). Belirlenen değişkenler arasındaki eş bütünleşme ilişkisi (10) numaralı denklem yardımıla tahmin edilmektedir. Denkleme, LeeStrazicich birim kök testinde bağımlı değişkenden elde edilen kırılma tarihi olan 1999 yılı eklenmiştir.

$$
\begin{aligned}
& \Delta Y_{t}=\vartheta_{0}+\sum_{i=1}^{m} \vartheta_{1 i} \Delta Y_{t-i}+\sum_{i=0}^{m} \vartheta_{2 i} \Delta X_{1 t-i}+\sum_{i=0}^{m} \vartheta_{3 i} \Delta X_{2 t-i}+\sum_{i=0}^{m} \vartheta_{4 i} \Delta X_{3 t-i}+\emptyset_{1} Y_{t-1}+ \\
& \emptyset_{2} X_{1 t-1}+\emptyset_{3} X_{2 t-1}+\emptyset_{4} X_{3 t-1}+\emptyset_{5} D_{1999}+\varepsilon_{t}
\end{aligned}
$$

\subsection{Toda-Yamamoto Nedensellik Testi}

Serilerin durağan olması ya da seriler arasında eş bütünleşme ilişkisinin olması gibi Granger nedesellik testi, zorunluklarına ihtiyaç duymayan Toda -Yamamoto nedensellik testi bu koşulları sağlamayan seriler için de VAR modeli kurularak WALD 
testinin uygulanabileceğini ileri sürmektedir (Dereli ve Akiş, 2019, s. 473). Uygulanacak test için $\left[\mathrm{k}+\left(\mathrm{d}_{\max }\right)\right]$ dereceden VAR modeli tahmin edilmekte ve katsayılar matrisinin k tanesine MWALD testi yapılmaktadır (Yenice ve Yenisu, 2019, s. 1073). Burada $\mathrm{k}$; optimal gecikme uzunluğunu, $\mathrm{d}_{\text {max }}$ : maksimum bütünleşme derecesini belirtmektedir. Test için gerekli VAR modeli aşağıda gösterilen (11) ve (12) numaralı denklemler ile oluşturulmaktadır:

$$
\begin{gathered}
Y_{t}=\alpha_{0}+\sum_{i=1}^{k} \emptyset_{1 i} Y_{t-i}+\sum_{j=k+1}^{d_{\max }} \emptyset_{2 j} Y_{t-j}+\sum_{i=1}^{k} \vartheta_{1 i} X_{t-i}+\sum_{j=k+1}^{d_{\max }} \vartheta_{2 j} X_{t-j}+\varepsilon_{1 t} \\
X_{t}=\alpha_{1}+\sum_{i=1}^{k} \lambda_{1 i} X_{t-i}+\sum_{j=k+1}^{d_{\max }} \lambda_{2 j} X_{t-j}+\sum_{i=1}^{k} \delta_{1 i} Y_{t-i}+\sum_{j=k+1}^{d_{\max }} \delta_{2 j} Y_{t-j}+\varepsilon_{2 t}
\end{gathered}
$$

(9) ve (10) numaral1 denklemler ile $H_{0}=\vartheta_{1}=0$ ve $H_{0}=\delta_{1}=0$ hipotezleri sinanmaktadır. Söz konusu hipotezler reddedilirse $X^{\prime}$ ten $Y^{\prime}$ ye doğru ve $Y^{\prime}$ den $X^{\prime}$ e doğru nedenselliğin varlığı kabul edilmektedir. Aksi takdirde bu değişkenler arasında nedensellik ilişkisi bulunmamaktadır.

\subsection{Ekonometrik Bulgular}

Araştırmada kullanılan tek yapısal kırılmalı Lee-Strazicich birim kök testi, ARDL sınır testi ve Toda -Yamamoto nedensellik testi sonuçlarına bu bölümde değinilecektir. Tablo; 2, sonuçlarına göre çıtı dengesi, tasarruf- yatırım dengesi ile bütçe dengesi birinci mertebeden durağan bulunurken, cari denge düzey değerinde ise durağan olarak elde edilmiştir. Ayrıca analizin bağımlı değişkeni olan GSYHD, yani çıktı dengesinin düzey değerinde ki kırılma tarihi olan 1999 yılı ARDL sınır testi analizinde kukla değişken olarak yer alacaktır. 
Tablo 2. Lee-Strazicich Birim Kök Testi Sonuçları

\begin{tabular}{|c|c|c|}
\hline Değişken & Kritik Değer & Kırılma Tarihi \\
\hline \multicolumn{3}{|c|}{ Panel A: Düzey } \\
\hline GSYHD & $-3.707(3)$ & 1999 \\
\hline YTD & $-3.449(8)$ & 1997 \\
\hline CD & $-4.435(11)$ & 1997 \\
\hline BD & $-2.550(10)$ & 2002 \\
\hline \multicolumn{3}{|c|}{ Panel B: Birinci Fark } \\
\hline$\Delta$ GSYHD & $-4.820(5)^{* * *}$ & 2014 \\
\hline$\Delta \mathrm{YTD}$ & $-6.464(1)^{* * *}$ & 2005 \\
\hline$\Delta \mathrm{CD}$ & - & - \\
\hline$\triangle \mathrm{BD}$ & $-5.306(3)^{* * *}$ & 2002 \\
\hline
\end{tabular}

Not: Birim kök testinde Crash Modeli kullanılmıştır. Optimal gecikme uzunlukları otomatik olarak belirlenmiş ve parantez içerisinde gösterilmiştir. $\quad$ *** \%1 düzeyinde anlamlılığı ifade etmektedir.

ARDL sınır testi kapsamında eş bütünleşme analizi için öncelikle VAR modeli yardımıla serilerin optimal gecikme uzunlukları Tablo; 3’ de görülmektedir.

$\mathrm{Bu}$ çalışma özelinde kurulan regresyon modeli için uygun gecikme uzunluğu; AIC kabul edilerek 4 birim olarak belirlenmiştir.

Tablo 3. VAR Gecikmesi Uzunluğunun Belirlenme Kriterleri

\begin{tabular}{c|c|c|c|c|c}
\hline Gecikme Uzunluğu & LR & FPE & AIC & SIC & HQ \\
\hline 0 & NA & 1614.852 & 18.73843 & 18.91983 & 18.79947 \\
1 & 91.02661 & 166.5135 & 16.45718 & $17.36415^{*}$ & $16.76235^{*}$ \\
2 & 20.36519 & 197.0511 & 16.57833 & 18.21088 & 17.12763 \\
3 & 26.34596 & 157.4863 & 16.23073 & 18.58886 & 17.02417 \\
4 & 21.68701 & $138.3797^{*}$ & $15.84498^{*}$ & 18.92870 & 16.88256 \\
\hline
\end{tabular}

Not: LR: Yarı modifiye LR test istatistiği; FPE: Son tahmin hatası; AIC: Akaike bilgi kriteri; SIC: Schwarz bilgi kriteri; HQ:

Hannan-Quinn bilgi kriteri. "ilgili kritere göre optimal gecikme uzunluğunu ifade eder.

Tablo 4' de yer alan sonuçlara göre bağımlı değişkenin çıktı dengesi ve bağımsız değişkenlerin yatırım / tasarruf dengesi, cari denge ve bütçe dengesi olan modelden elde edilen F-istatistik değeri 16.802 olarak belirlenmiştir. Bu bağlamda belirlenen değer Pesaran vd.'nin (2001) belirlenen \%1 kritik üst limit değerinden büyük olması nedeniyle değişkenler arasındaki eş bütünleşme ilişkisi kanıtlanmaktadır. Ayrıca tanısal testlerden elde edilen sonuçlara göre kurulan regresyon modeli otokorelasyon ve değişen varyans gibi problemler barındırmamakla birlikte normal bir dağılıma sahiptir. 
Tablo 4. ARDL Sınır Testi Eşbütünleşme Sonuçları

\begin{tabular}{|c|c|c|}
\hline \multicolumn{3}{|c|}{ Kisitsız Sabit Terimli ve Kısıtsız Trendli Model } \\
\hline $\begin{array}{l}\text { Model } \\
\text { ARDL gecikme uzunluğu } \\
\text { AIC uygun gecikme uzunluğu } \\
\text { Hesaplanan F istatistiği } \\
\text { Anlamlılık seviyesi } \\
\% 1 \\
\% 2,5 \\
\% 5 \\
\% 10\end{array}$ & $\begin{array}{l}\text { Alt } I(0) \\
4.40 \\
3.89 \\
3.47 \\
3.03\end{array}$ & $\begin{array}{l}\text { Üst } I(1) \\
5.72 \\
5.07 \\
4.57 \\
4.06\end{array}$ \\
\hline \multicolumn{3}{|l|}{ Tanisal Testler } \\
\hline $\begin{array}{l}R^{2} \\
\text { Adjusted- } R^{2} \\
F \text {-istatistiği } \\
\text { Breusch-Godfrey LM testi } \\
\text { ARCH LM testi } \\
\text { J-B normality test }\end{array}$ & $\begin{array}{c}0.939 \\
0.862 \\
0.125 \\
1.655(0.220) \\
0.125(0.725) \\
0.406(0.816) \\
\end{array}$ & \\
\hline
\end{tabular}

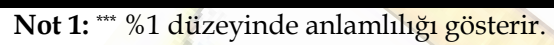

Not 2: Tablo kritik değerleri Pesaran vd. (2001) tarafından belirtilen kısıtlanmamış sabitli ve kısıtlanmamış trendli kritik değer tablosundan elde edilmiştir

Tablo 5'de Seemingly Unrelated Regression (SUR) yöntemiyle belirlenen Toda -Yamamoto nedensellik analizi sonuçlarına göre çalışmada kullanılan tüm değişkenler arasında karşılıklı bir nedensellik ilişkisi tespit edilmiştir. Yani 1983-2019 döneminde Türkiyenin verileri için bağımlı değişken olan çıktı dengesinin, bağımsız değişken olan yatırım / tasarruf dengesine, cari dengeye ve bütçe dengesine neden olurken aynı şekilde yatırım / tasarruf dengesi, cari denge ve bütçe dengesi de, çıktı dengesinin nedeni olarak görülmektedir.

Tablo 5. Toda-Yamamoto Nedensellik Testi Sonuçları

\begin{tabular}{|c|c|c|c|}
\hline \multirow[b]{2}{*}{ HIIPOTEZLER } & \multirow[b]{2}{*}{$\mathrm{k}+\mathrm{d}_{\max }$} & \multicolumn{2}{|c|}{ SUR } \\
\hline & & $\chi^{2}$-istatistiği & Nedensellik \\
\hline YTD $=>$ GSYHD & $4+1$ & $19.663^{* * *}$ & VAR \\
\hline GSYHD $=>$ YTD & $4+1$ & $59.597^{* * *}$ & VAR \\
\hline $\mathrm{CD}=>$ GSYHD & $4+1$ & $52.820^{* * *}$ & VAR \\
\hline GSYHD $=>C D$ & $4+1$ & $35.982^{* * *}$ & VAR \\
\hline $\mathrm{BD}=>\mathrm{GSYHD}$ & $4+1$ & $95.939^{* * *}$ & VAR \\
\hline GSYHD $=>$ BD & $4+1$ & $9.517^{*}$ & VAR \\
\hline $\mathrm{YTD}=>\mathrm{CD}$ & $4+1$ & $11.389^{* *}$ & VAR \\
\hline $\mathrm{CD}=>\mathrm{YTD}$ & $4+1$ & $47.768^{\star * *}$ & VAR \\
\hline $\mathrm{YTD}=>\mathrm{BD}$ & $4+1$ & $13.526^{* *}$ & VAR \\
\hline $\mathrm{BD}=>\mathrm{YTD}$ & $4+1$ & $87.305^{* * *}$ & VAR \\
\hline $\mathrm{CD}=>\mathrm{BD}$ & $4+1$ & $24.336^{* * *}$ & VAR \\
\hline $\mathrm{BD}=>\mathrm{CD}$ & $4+1$ & $48.218^{* * *}$ & VAR \\
\hline
\end{tabular}




\section{SONUÇ}

Çalışmada uygulanan ekonometrik metodoloji üç bölümden oluşturulmuştur. Birinci bölümde; serilerin durağanlık seviyeleri yapısal kırılmalı Lee-Strazicich birim kök testi kullanılarak gerçekleştirilmiş, ikinci bölümde; değişkenler arasındaki eşbütünleşme ilişkisinin varlığı Pesaran vd. tarafından geliştirilen ARDL sınır testi çerçevesinde belirlenmiştir. Nihai olarak da değişkenler arasındaki nedensellik ilişkisinin varlığı ve yönü Toda-Yamamoto nedensellik analizi ile araştırılmıştır. Çalışmada kullanılan GSYHD, YTD, CD ve BD serileri Strateji ve Bütçe Başkanlığı (2020) ile Dünya Bankası (2020) veri sitesinden derlenerek oluşturulmuştur. Regresyon modelinde yer alan a1, a2 ve a3 katsayıları sırasılla yatırım ve tasarruf dengesinin, cari dengenin ve bütçe dengesinin, çıtı dengesi üzerindeki uzun dönemli etkisini göstermektedir. Geleneksel birim kök testlerinde kırılmaların yok sayılması uygulanan testin yanıltıcı sonuçlar vereceği düşüncesinden hareketle çeşitli yapısal kırılmalı birim kök testleri öne çıkmaktadır. Tablo; 2, sonuçlarına göre çıktı dengesi, yatırım ve tasarruf dengesi ile bütçe dengesi birinci mertebeden durağan bulunurken cari denge düzey değerinde durağan olarak elde edilmiştir. Seemingly Unrelated Regression (SUR) yöntemiyle belirlenen Toda-Yamamoto nedensellik analizi sonuçlarına göre çalışmada kullanılan tüm değişkenler arasında karşılıklı nedensellik ilişkisi tespit edilmiştir. Yani 1983-2019 dönemi Türkiye verileri için bağımlı değişken olan çıktı dengesi, bağımsız değişken olan yatırım/tasarruf dengesine, cari dengeye ve bütçe dengesine neden olurken aynı şekilde yatırım/tasarruf dengesi, cari denge ve bütçe dengesi, çıktı dengesinin nedenidir. Yapılan ampirik incelemeler sonucunda dördüz açıklar hipotezinin Türkiye için geçerli olduğu kanısına varılmıştır. Türkiye ekonomisinin kırılgan yapısının onarılabilmesi ve tam istihdam hasıla düzeyine ulaşabilmesi için gerekli olan iç ve dış reel yatırımlar ile bu yatırımları finanse edebilecek ulusal ve uluslararası tasarrufların aktif bir biçimde işletilebilmesine bağlıdır. Yatırımların finansmanı için gerekli olan tasarruflar ülke genelinde yetersiz olduğundan, tasarruf artırıcı tedbirlerin de alınması gerekmektedir. Türkiyenin tasarruflarını pozitif yönde etkileyecek olan en önemli unsur ise cari açıkların azaltılıp, hatta cari işlemler fazlası verebilecek bir üretim - ithalat ve ihracat rejimine yönelmek gerekmektedir. 
Türkiye ekonomisinde yaşanan ekonomik kırılganlıkların temelinde yer alan dördüz açıkların ekonomiyi sürekli tehdit eder pozisyonda olmasının önüne geçilmesi için bu açıkların sürekliliğinin ortadan kaldırılması gerekmektedir. Öncelikli olarak ekonomide makroekonomik yapısal regülasyonlar yapılarak ekonominin üretim gücünün yükseltilmesi gerekmektedir. Yani Türkiye ekonomisinin reel GSYH'nın potansiyel GSYH'ya yakın değerlerde gerçekleşmesi gerekmektedir. Yatırımların finansmanı için gerekli olan tasarruflar ülke genelinde yetersiz olduğundan, tasarruf artırıcı tedbirlerin de alınması gerekmektedir. Türkiyenin tasarruflarını pozitif yönde etkileyecek olan en önemli unsur ise cari açıkların azaltılıp, hatta cari işlemler fazlası verecek bir üretim - ithalat ve ihracat rejimine yönelmek gerekmektedir. Bunun için ülke ekonomisinin yapısı yüksek verimliliğe dayalı, yüksek teknoloji temelli bir üretim yapısına dönüşmelidir. Yüksek teknolojiye dayalı bir üretim seviyesine ise Ar-Ge yatırımlarına önem verilen ve innovasyonun desteklendiği bir ekonomi anlayışına yönelinmelidir. Üretimde rekabet gücü yüksek olan bir ekonomi dış ticaret fazlası vererek çıktı açığının pozitif bir eğilime dönmesini sağlayacaktır. Ekonominin ihracata dayalı büyüme serüveninde cari açık pozisyonundan cari fazla veren bir ekonomiye dönüşmesi kamu bütçe gelirlerine olumlu yansıyarak bütçe açıkları pozisyonunu da azaltacaktır. Bu durum otomatik olarak ekonomi içinde hem özel kesimde, hem de kamu kesiminde tasarrufların artışına neden olarak yatırımlar için gerekli olan fonlara (iç tasarruflara) yönelimini sağlayacak ve cari açık üzerinde pozitif bir düzelmeye neden olacaktır. Bu sonuç itibariyle hem kamu bütçe dengesindeki açıklar azalacak, hem de tasarruf-yatırım açı̆̆ı ortadan kalkacaktır. 


\section{KAYNAKÇA}

Akıncı Mert \& Akıncı Gönül Yüce \& Yılmaz Ömer. (2016). “Dördüz Açıklar; Ütopya mı Yoksa Gerçek mi?", PARADOX Ekonomi, Sosyoloji ve Politika Dergisi, Ocak 2016, Cilt 12. Sayı 1. Sayfa 22-47.

Çetin, Ahmet. (2014). "Kamu Borçlarının Makroekonomik Etkileri: Ampirik Bir Analiz", https://www.researchgate.net/publication/293885743_Kamu_Borclarinin_Makroekonomik_Etkileri_ Ampirik_Bir_Analiz.

Dereli, D. D. ve Akiş, E. (2019). “Türkiye' de Turizm Gelirleri ile İktisadi Büyüme Arasındaki İlişkinin Analizi (1970-2016)". Atatürk Üniversitesi İktisadi ve İdari Bilimler Dergisi, 33(2): 467-478.

Göçer, İ \& Akın, T. (2016). “Kırılgan Beşlide Tasarruf-Yatırım Açı̆ııınEkonomik Büyümeye Etkileri:Yeni Nesil Bir Ekonometrik Analiz", Ege Akademik Bakış Dergisi, Cilt 16 Sayı 2, Nisan 2016. Ss. $197-210$.

İpek, Evren. \& Kızılgöl, Özlem Ayvaz. (2016). "Türkiye Ekonomisinde Üçüz Açık”. Ege Akademik Bakış. Cilt 16-Sayı 3. Temmuz 2016.

Karanfil, M. \& Kılıç, C. (2015). “Türkiye Ekonomisinde Üçüz Açık Hipotezinin Geçerliliği: Zaman Serisi Analizi", Uluslararası Yönetim İktisat ve İşletme Dergisi, Cilt 11, Sayı 24.

Kaygısız, A.Ş. \& Kaya, D. G. \& Kösekahyaoğlu, L. (2016). “Türkiye’de Tasarruf, Yatırım, Cari Açık ve Büyüme:1980-2014 Dönemi Üzerine Bir Ndenesellik İlişkisi Analizi", Çankırı Karatekin Üniversitesi, Sosyal Bilimler Enstitüsü Dergisi, 7 (1): 273-300.

Lee, J. ve Strazicich, M. C. (2004). “Minimum LM unit root test with one structural break". Appalachian State University Working Papers, 04-17: 1-15.

Mankiw, Gregory (2009). Makro Ekonomi, Çev. Ömer Faruk Çolak, Eflatun Yayınevi, Ankara. ISBN:978-605-4160-38-9.

Pesaran M.H., Shin Y., Smith R. (2001). "Bounds testing approaches to the analysis of level relationships". Journal of Applied Econometrics, 16: 289-326.

Şahin, G. ve Gökdemir, L. (2016). “İnsani Gelişme Endeksi Bileşenlerinin Türkiye Ölçeğinde Ardl Sınır Testi İle Sınanması". Gazi İktisat ve İsletme Dergisi, 2(1): 1-24.

Tabar, Ç. ve Çetin, I. (2016). “Türkiye Ekonomisi Özelinde Phillips Eğrisi Analizi”. Journal of Life Economics, 3(4): 79-100. 
Toda, H. Y. and Yamamoto, T. (1995). "Statistical inference in vector autoregressions with possibly integrated processes". Journal of Econometrics, 66: 225-250.

Tülümce, S. Y. (2013). “Türkiye’ de Üçüz Açığın Ampirik Analizi (1984-2010)”, Maliye Dergisi, Sayı; 165. Temmuz-Aralık 2013.

Ünsal, E. (2009), Makro İktisat, Ankara: İmaj Yayıncılık.

Yenice, S. ve Yenisu, E. (2019). Türkiye' de Döviz Kuru, Enflasyon Ve Faiz Oranlarının Etkileşimi. Dokuz Eylül Üniversitesi Sosyal Bilimler Enstitüsü Dergisi, 21(4): 1065-1086.

Yıldırım, Kemal \& Karaman, Doğan \& Taşdemir, Murat. (2009). Makro Ekonomi, Ekonomi Kitapları Dizisi:26, Seçkin Yayıncılık ve Tic. A.Ş. İstanbul. ISBN:978-975-02-1053-2.

T.C. Cumhurbaşkanlığı Strateji ve Bütçe başkanlığı. (2020). http://www.sbb.gov.tr/ekonomik-veriler (Erişim Tarihi: 22.03.2020).

Worldbank. (2020). https:// data.worldbank.org (Erişim Tarihi: 22.03.2020). 